\title{
Analysis of the periodontal status of patients with mandibular-bonded retainers
}

\author{
Análise da condição periodontal de pacientes portadores de \\ contenção ortodôntica ântero-inferior fixa
}

\begin{abstract}
Purpose: This clinical study evaluated the periodontal status of patients with bonded retainers as compared to a non-treated control group.

Methods: Forty dental students were included in the sample and divided into the following two groups: 1) a test group of 20 subjects that, after orthodontic treatment, have been bonded retainer users for at least 2 years and 2) a control group of 20 patients that never experienced orthodontic treatment nor used any bonded retainer. The region associated with the retainer in the test group and the lower canine-to-canine region in the control group were examined according to the following clinical parameters: plaque index (PI), bleeding on probing (BOP), gingival recession (GR), clinical attachment level (CAL) and probing depth (PD).

Results: No differences were observed for $G R$ or BOP $(P>0.05)$. In contrast, the test group showed higher values of CAL and PD at proximal sites when compared to controls $(P<0.05)$. In addition, IP was significantly increased at buccal and lingual sites $(P<0.05)$.

Conclusion: The placement of orthodontic bonded retainers negatively affected periodontal health, resulting in increased PI, PD and CAL.
\end{abstract}

Key words: Periodontium; orthodontic anchorage procedures; dental plaque

\section{Resumo}

Objetivo: Este estudo avaliou clinicamente a condição periodontal de pacientes portadores de contenção ortodôntica ântero-inferior fixa comparando com um grupo que nunca fez uso desse aparato ortodôntico.

Metodologia: Foram selecionados para o estudo 40 voluntários, estudantes de Odontologia, divididos em dois grupos. Grupo teste: 20 pacientes que fizeram uso de contenção ortodôntica fixa por mais de 2 anos; e grupo controle: 20 pacientes que nunca utilizaram qualquer tipo de contenção fixa. Os dentes ântero-inferiores envolvidos pela contenção no grupo teste, e de canino-a-canino no grupo controle, foram examinados segundo os seguintes parâmetros clínicos: Índice de placa (IP), sangramento à sondagem (SS), posição da margem gengival (PMG), nível de inserção clínica (NIC) e profundidade de sondagem (PS).

Resultados: Não foram observadas diferenças significantes entre os grupos para recessão gengival e sangramento à sondagem $(P>0,05)$. Já para o nível de inserção clínica e profundidade de sondagem observaram-se diferenças significantes $(P<0,05)$ em relação às faces proximais. Além disso, um maior acúmulo de placa (IP) foi detectado nas faces livres $(P<0,05)$.

Conclusão: A contenção ortodôntica ântero-inferior fixa influenciou negativamente a condição periodontal em relação aos índices IP, NIC e PS.

Palavras-chave: Periodonto; procedimentos de ancoragem ortodôntica; placa dental

\author{
João Batista César Neto a \\ Miguel Roberto Simões Régio ${ }^{\text {b }}$ \\ Josué Martos ${ }^{\mathrm{c}}$ \\ Francieli Spautz d \\ Giliani Bizarello de Moraes ${ }^{d}$
}

a Department of Stomatology, School of Dentistry, University of São Paulo, São Paulo, SP, Brazil

${ }^{b}$ Department of Preventive Dentistry, School of Dentistry, Federal University of Pelotas, Pelotas, RS, Brazil

c Department of Clinics, School of Dentistry, Federal University of Pelotas, Pelotas, RS, Brazil

d Graduate Program, School of Dentistry, Federal University of Pelotas, Pelotas, RS, Brazil

\author{
Correspondence: \\ João Batista César Neto \\ Disciplina de Periodontia - Departamento de \\ Estomatologia \\ Faculdade de Odontologia - Universidade de \\ São Paulo (USP) \\ Av. Prof Lineu Prestes, 2227 \\ São Paulo, SP - Brasil \\ 05508-900 \\ E-mail: jbcesarneto@usp.br
}

Received: November 6, 2009

Accepted: April 9, 2010

Conflict of Interest Statement: The authors state that there are no financial and personal conflicts of interest that could have inappropriately influenced their work.

Copyright: (C) 2010 César Neto et al.; licensee EDIPUCRS. This is an Open Access article distributed under the terms of the Creative Commons AttributionNoncommercial-No Derivative Works 3.0 Unported License. 


\section{Introduction}

Orthodontic treatment aims to make a facial appearance aesthetically pleasing, allow for efficient mastication, bypass or correct an occlusion, and improve dental and periodontal health. When orthodontic therapy is finished, it is necessary to control the new dental positions and occlusal relationships (1). Orthodontic bonded retainers, which allow a period for reorganization and stabilization of tissues after removal of orthodontic apparatuses, are important for this control. Nevertheless, teeth suffer constant pressure from adjacent soft tissues in some clinical situations, causing recurrences with subsequent injury to the final orthodontic procedure $(1,2)$.

The orthodontic bonded retainer phase, which was established after orthodontic treatment, is an important step toward maintenance of the treatment results and occlusal stability. In relation to recurrence, the region of greatest concern is the incisors (3-6).

The amount of time a patient is required to wear orthodontic bonded retainers for the lower incisors is related to the patient's age, the characteristics and severity of crowding, the dental discrepancy initial, the orthodontic biomechanics employed, the clinical experience of the orthodontist, and the patient's ability to maintain proper hygiene $(7,8)$. There is no way to predict which cases will present clinical relapses or when it might occur, so the duration of this phase is often unclear $(9,11)$.

It has been described in the literature that the biggest drawback in the use of fixed orthodontic bonded retainers is the difficulty of maintaining proper hygiene in the region, allowing for the accumulation of plaque and favoring the appearance of gingivitis and periodontal damage over time (5,11-16).

There is a lack of studies evaluating the periodontal status of patients utilizing orthodontic bonded retainers for the lower incisors over a long period of time. Thus, this study aims to evaluate clinically the periodontal status of patients with orthodontic retainers for mandibular incisors for over two years.

\section{Methodology}

The present study is a cross-sectional evaluation of periodontal condition in patients who use fixed orthodontic bonded retainers for mandibular teeth. The research protocol was submitted to and approved by the institutional review board. Forty volunteers of both sexes were selected for the study. The volunteers were dentistry students from the institution, and exclusion criteria were the presence of periapical or pulpal changes, smoking, the presence of a relevant systemic disease, or the administration of drugs that could, with continued use, interfere with the pathogenesis of a periodontal disease. Selected students signed a consent form and became part of the study. Students were divided into the following two groups: a test group (TG) composed of 20 volunteers ( 15 women and 5 men) who were using orthodontic fixed bonded retainers for at least 2 years, and a control group (CG) composed of 20 volunteers (11 women and 9 men) who never used any type of retainer.

Prior to the clinical evaluation, all patients in the test group answered a questionnaire about their knowledge of the bonded retainer and the time of their orthodontic use. In addition, the examiner went through a process of training and calibration in 16 randomly selected patients, who were examined at 2 different times. The probing depth and gingival recession were measured at 6 sites for each selected tooth $(31,32$ and 41$)$. Clinical examination of patients was repeated at an interval of one week. The kappa index was 0.99 for probing depth and 0.98 for gingival recession. For the visible plaque index and gingival bleeding, training with clinical photographs was performed prior to evaluation of patients for the identification of these two conditions. Examination of the patients began after this training and calibration.

We examined the lower anterior teeth at 6 sites per tooth (mesiobuccal, buccal, disto-buccal, disto-lingual, lingual and mesio-lingual) according to the following clinical parameters (17): visible plaque index - PI: 0 -absence of visible plaque, 1-presence of visible plaque expressed as a percentage; Bleeding index - BOP: 0-absence of bleeding, 1-presence of bleeding expressed as a percentage; Gingival recession - GR: distance from the free gingival margin to the cemento-enamel junction in millimeters; Clinical attachment level-CAL: distance from the cemento-enamel junction to the base, clinically detectable in the gingival sulcus or periodontal pocket in millimeters; Probing depth - PD: distance from gingival margin to the base, clinically detectable in the gingival sulcus or periodontal pocket in millimeters.

Overall averages were obtained for each patient after considering all the dental surfaces evaluated. Data were also stratified for the free and proximal surfaces. For PI and BOP, which are qualitative variables, we used the nonparametric Mann-Whitney test $(\alpha=0.05)$ for the comparison between the two groups. For the numerical parameters (PD, GR and CAL), the Kolmogorov-Smirnov test was applied initially to see if there was a normal distribution. In cases of normal distribution, a non-paired t test $(\alpha=0.05)$ was used for comparison between the groups. In the absence of a normal distribution, we used the nonparametric Mann-Whitney test $(\alpha=0.05)$.

\section{Results}

The results for the evaluated parameters in the test and control groups are presented in Tables 1 and 2. The time recommended by the orthodontist for the use of fixed orthodontic retainers and the usage time of the retainer in the test group are shown in Figures 1 and 2, respectively. There were no significant differences between the groups for gingival recession (GR) or gingival bleeding index (BOP) $(P>0.05)$. As for the visible plaque index (PI), clinical attachment level (CAL) and probing depth (PD), there were 
Table 1. Mean plaque index (PI) and bleeding index (BOP) on the proximal and free faces in the test and control groups.

\begin{tabular}{lcccccc}
\hline & \multicolumn{3}{c}{ PI } & \multicolumn{3}{c}{ BOP } \\
\hline & Control & Test & P & Control & Test & P \\
\hline Proximal face & $0 \pm 0$ & $0.04 \pm 0.20$ & $>0.05$ & $0.01 \pm 0.05$ & $0.05 \pm 0.22$ & $>0.05$ \\
Free face & $0.02 \pm 0.06$ & $0.13 \pm 0.2$ & $<0.05$ & $0.05 \pm 0.07$ & $0.13 \pm 0.24$ & $>0.05$ \\
\hline
\end{tabular}

Table 2. Mean probing depth (PD), clinical attachment level (CAL) and gingival recession (GR) on the proximal and free faces in the test and control groups.

\begin{tabular}{lccccccccc}
\hline & & PD & & & GR & \multicolumn{2}{c}{ CAL } \\
\hline & Control & Test & P & Control & Test & P & Control & Test & P \\
\hline Proximal face & $1.57 \pm 0.27$ & $1.91 \pm 0.43$ & $<0.05$ & $0.00 \pm 0.00$ & $0.00 \pm 0.00$ & $>0.05$ & $1.57 \pm 0.27$ & $1.91 \pm 0.43$ & $<0.05$ \\
Free face & $1.02 \pm 0.05$ & $1.07 \pm 0.11$ & $>0.05$ & $0.1 \pm 0.04$ & $0.22 \pm 0.42$ & $>0.05$ & $1.11 \pm 0.43$ & $1.29 \pm 0.41$ & $>0.05$ \\
\hline
\end{tabular}
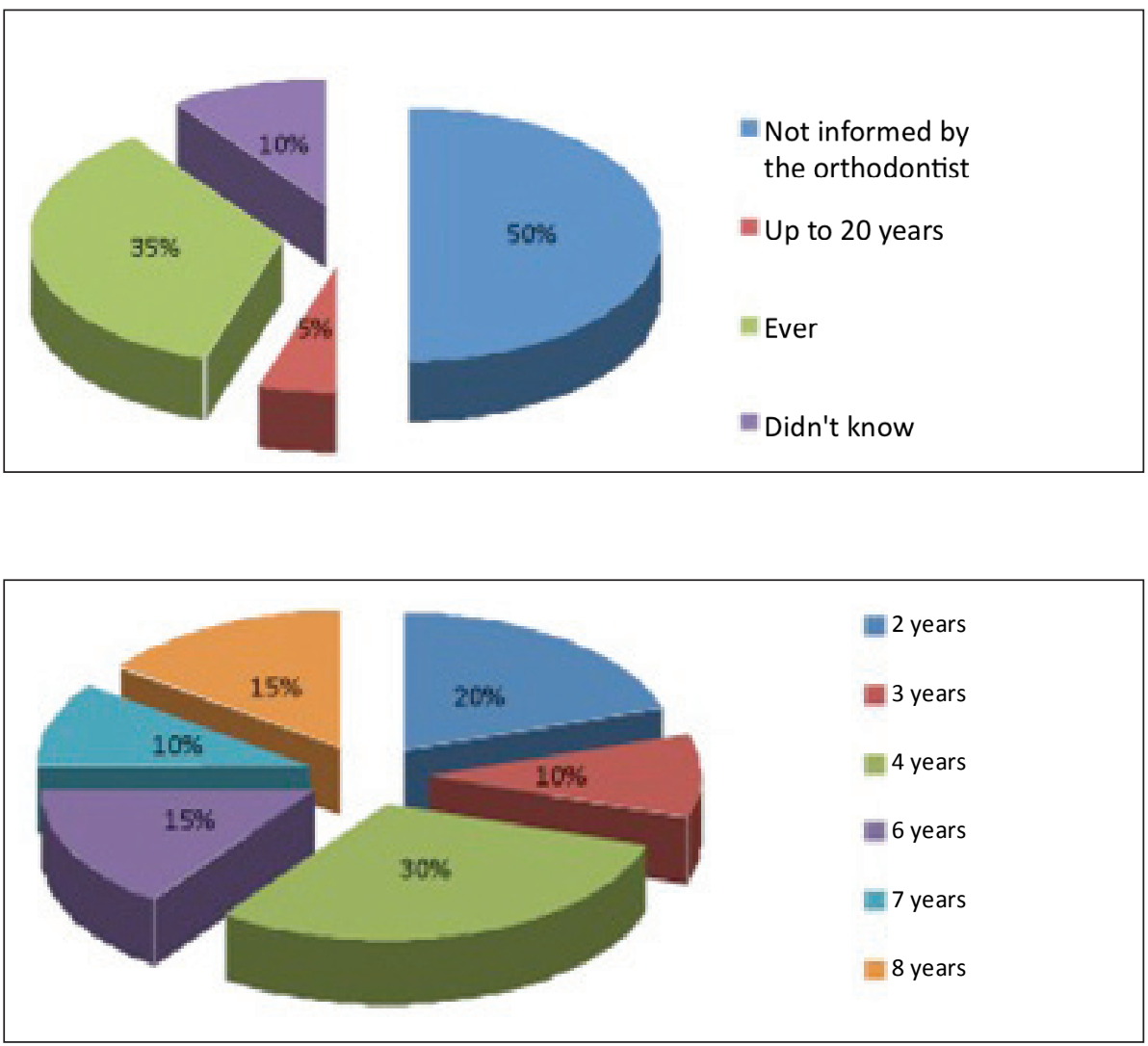

Fig. 1. Time recommended by the orthodontist for the use of orthodontic bonded retainers.
Fig. 2. Time of use of orthodontic bonded retainers in the test group. significant differences when the results were stratified by face. The free surfaces observed a greater accumulation of plaque (PI) in the test group compared to the control group $(P<0.05)$.

The test group showed greater probing depth (PD) and attachment loss $(\mathrm{CAL})(P<0.05)$ on the proximal surfaces when compared to controls, while significant differences between groups were not detected for the free surfaces.

\section{Discussion}

This study compared the periodontal status of carriers and non-carriers of fixed orthodontic retainers in the lower canine-to-canine region. The results showed that there were statistically significant differences between the groups for PI, CAL and PD, showing an influence of the orthodontic bonded retainer on the periodontium.

The results of this study showed that there was a greater accumulation of plaque in the test group compared to the control group, which was expected, because the presence of orthodontic bonded retainers hinders access to proper hygiene $(5,11,14-16)$. Similar results were reported by Artun et al. (14), who found a greater accumulation of plaque in the interproximal surfaces of teeth with fixed bonded retainers when compared to teeth associated with removable retainers. Other authors also studied the impact of fixed retainers on periodontal health and there was a general agreement with this result $(15,18)$. 
One of the most relevant results of this study refers to the CAL. A statistically significant difference for this parameter was detected when the results were stratified by face, and this difference was observed only for the proximal surfaces. The presence of bonded retainers makes proximal difficult hygiene and requires the use of a pass-wire, which may at least in part explain the results. Changes to CAL are irreversible and cumulative in nature, emphasizing the importance of the presence of the plaque retention factor. As this sample is composed of young patients with good hygiene standards, CAL differences were not expected. Although 2 patients have used the orthodontic bonded retainers for about two years, most patients have used them for more than 4 years, and within this period they may have passed through stages of attachment loss. Similar findings were reported by Shirasu et al. (16) in a study evaluating 15 patients.

The results of PD were similar to CAL, increased in the patients with orthodontic bonded retainers. The association of increased probing depth, clinical attachment loss and greater accumulation of plaque in the test group strengthens the likelihood of future attachment loss in patients with bonded retainers.

The presence of excess material to fix the orthodontic bonded retainers may also have favored the changes in the clinical parameters on the proximal surfaces (16) because many patients had this characteristic. This hypothesis is strengthened by the fact that all the volunteers in the test group reported daily use of dental floss, and yet had significant CAL and PD values at the proximal face, showing the difficulty of cleaning this area. These findings reinforce the importance of proper planning and installation of orthodontic bonded retainers and proper instructions on its hygiene, as well as the importance of adapting retainer design to each area, type, and dental anatomy, $(1,5,12,19)$. There were no statistically significant differences for bleeding on probing and gingival recession (Tables 1 and 2). In relation to gingival recession this result was expected because the sample consisted of young patients, i.e. with shorter exposure to risk factors for recession (plaque and mechanical trauma). Moreover, as differences were observed for CAL and $\mathrm{PD}$, it was expected that bleeding would accompany these parameters because the gingival inflammation is a factor that precedes the insertion loss. The absence of this correlation may have been caused by a momentary factor, i.e. that time there was a balance between local factors and the host response. It is known that periodontal disease has periods of remission and exacerbation and that one's course is not linear; therefore, parameters such as gingival bleeding, plaque accumulation and even probing depth may not correlate directly with the insertion loss that presents with a cumulative factor.

During the examinations, it was observed that nineteen of the twenty orthodontic bonded retainers were classic (holding canine canine-to-wire tangent to the lingual surface of teeth evolving unwrinkled, releasing the proximal surface), of which 9 had flat wire and composite resin on all teeth and 6 others had woven wire and composite resin on all teeth. Another type that contained flat wire and composite resin only on the canines was found in 3 patients. One was of woven wire and had composite resin only on the canines. Only 1 modified type retainer was evaluated (with containment that had folds in the wire, releasing the proximal surface), which spanned from lateral incisor to lateral incisor and had resin on all the teeth.

For Artun (18), it did not matter what type of orthodontic wire or bonded retainer used, as there is a tendency for plaque accumulation along it that increases with time. In our study, we could not observe a correlation between the years of use of orthodontic bonded retainers and increased levels of PD, BOP or PI because we conducted a cross-sectional evaluation, although an attempt to associate the result obtained through the years of use of orthodontic bonded retainers has been performed. The present data suggest that the amount of material used for bonding the orthodontic retainer is the most crucial because it is the most important factor that hinders hygiene according to Cerny (15). In view of the observed results, we suggest that the technical quality of the placement of orthodontic bonded retainers is more important than the mere presence of this important device. Dahl and Zachrisson (20) state that the time of removal of orthodontic bonded retainers depends on factors such as the type of malocclusion, the patient's age, the motivation to maintain optimal results, and the patient's ability to maintain the bonded retainer clean. Other studies $(5,15,21)$ also agree with these factors, but add that this argument has been based more on assumptions than on long-term studies. In the sample study, no orthodontist explained the time required for the use or removal of the bonded retainer and of most of the volunteers reported that they had not received any information about the subject. Moreover, they were asked to return periodically for an evaluation regarding the evolution of their orthodontic and periodontal case.

To date, there is no protocol for determining the time length for orthodontic bonded retainer use, and it is up to the orthodontists to determine individualized treatment for each patient. Clinical negligence at this step may result in the future failure of the periodontal tissues even though good results have been achieved during the phase of active orthodontic movement. This information should be emphasized to patients because many did not return to the office after completion of orthodontic treatment and may be using orthodontic retainer devices without necessity.

Moreover, the retainer may have favored unnecessary damage to the periodontium. It is practically impossible to determine a patient's susceptibility to periodontal disease before the installation of the retainer (22). In addition, there is a short time of exposure to bacterial biofilms when evaluating young patients. The host susceptibility to infection may increase over time with exposure to other risk factors. This can change the in terms of motivational, and behavioral and systemic; hence, it is important to explain the risks to patients ahead of time in order to maintain the results achieved with orthodontic treatment. 
Therefore, patients should receive direct and detailed guidance on the importance of fixed retainers after the orthodontic treatment. The benefits and losses related to retainer use, the care needed for their maintenance, and the intervals for their reassessment must be clearly stated. Only in this way can complete success in addressing the various aspects of orthodontic treatment be achieved.

\section{Conclusions}

The results obtained in this study concluded that orthodontic bonded retainers may favor periodontal attachment loss and that there was not sufficient explanation to patients with anterior bonded orthodontic retainers on the timing of their removal.

\section{References}

1. Silva Filho OG, Kubitski MG, Marinho ET. Contenção fixa inferior 3X3: considerações sobre a confecção, colagem direta e remoção. R Clin Orto Dental Press 2004;3:17-24.

2. Ngervall B, Thuer U. Cheek pressured heal posture. Angle Orthod 1988; 58:47-57

3. Becker A, Karnei-R R. Effects of infraocclusion. Part 1. Tilting of the adjacent teeth and the local space loss. Am J Orthodon Dentofacial Orthop 1992;102:256-63.

4. Ciruffo P, Nover D. Contenção pós-tratamento ortodôntico. J Bras Ortod Ortop Maxilar 1997;2:5-11

5. Loriato LB, Machado AW, Vieira JM. Alternativas para fixação da contenção fixa ântero-inferior durante a colagem. Rev Clin Ortod Dental Press 2007;6:25-34

6. Richardson ME. The etiology of late lower arch crowding alternative to mesially directed forces: a review. Am J Orthodon Dentofacial Orthop 1994;6:592-597.

7. King GJ, Keeling SD. Orthodontic bone remodeling in relation to appliance decay. Angle Orthod 1995;65:129-40.

8. Tanne K. Biomechanical behavior of the periodontium before and after orthodontic tooth movement. Angle Orthod 1995;65:123-8.

9. Bramante MA. Controversies in orthodontics. Dent Clin North Am 1990;34:91-102.

10. Nanda RS, Nanda SK. Considerations of dentofacial growth in long-term retention and stability: is active retention needed? $\mathrm{Am} \mathrm{J}$ Orthod Dentofacial 1992;101:297-303.

11. Artun J, Spadafora AT, Shapiro PA. A 3-year follow-up study of various types oforthodontic canine-to-canine retainers. Eur J Orthod 1997; 19:501-509.

12. Bicalho JS, Bicalho KT. Descrição do método de contenção fixa com livre acesso do fio dental. R Dental Press Ortodon Ortop Facial $2001 ; 6: 97-104$
13. Heier EE, De Smit AA, Wiigaerts IA, Adriaens PA. Periodontal implications of bonded versus removable retainers. Am J Orthod Dentofacial Orthop 1997;1 12:607-16.

14. Artun J., Spadafora AT, Shapiro PA, McNeill RW, Chapko MK. Hygiene status associated with different types of bonded, orthodontic canine-to-canine retainers. A clinical trial. J Clin Periodontol 1987; 14:89-94

15. Cerny R. Permanent fixed lingual retention. J Clin Orthod $2001 ; 35: 728-732$.

16. Shirasu BK, Hayacibara RM, Ramos AL. Comparação de parâmetros periodontais após a utilização de contenção convencional $3 X 3$ plana e contenção modificada. R Dental Press Ortodon Ortop Facial 2007; 12:41-47.

17. Ainamo J, Bay I. Problems and proposals for recording gingivitis and plaque. Int Dent J 1975;25:229-35.

18. Artun J. Caries and periodontal reactions associated with long-term use of different types of bonded lingual retainers. Am J Orthod 1984;86:112-118.

19. Zachrisson BU. Third-generation mandibular bonded lingual 3-3 retainer. J Clin Orthod 1995;29:39-48.

20. Dahl EH, Zachrisson BU. Long-term experience with direct-bonded lingual retainers. J Clin Orthod 1991;25:619-630.

21. Gkantidis N, Christou P, Topouzelis N. The orthodontic-periodontic interrelationship in integrated treatment challenges: a systematic review. J Oral Rehabil 2010; 37:5.

22. Gomes Filho IS, Macedo TCN, Cruz SS, Soledade KR, Trindade SC, Sarmento VA. Comparação de critérios que determinam o diagnóstico clínico da doença periodontal. Rev Odonto Ciênc $2006 ; 21: 77-81$ 